\title{
Avaliação da tipologia dos resíduos de construção civil entregues nas usinas de beneficiamento de Belo Horizonte
}

\author{
Evaluation of the typology of construction waste delivered to processing \\ plants in Belo Horizonte, Brazil
}

\begin{abstract}
Daniel de Souza Carmo
Engenheiro de Produção Civil pela Universidade da Fundação Mineira de Educação e Cultura (FUMEC) - Belo Horizonte (MG), Brasil. Mestre em Engenharia

Civil pelo Departamento de Engenharia Civil do Centro Federal de Educação Tecnológica de Minas Gerais (CEFET-MG) - Belo Horizonte (MG), Brasil.
\end{abstract}

\section{Nilton da Silva Maia}

Doutor em Engenharia Mecânica pela Universidade Federal de Minas Gerais (UFMG) - Belo Horizonte (MG), Brasil. Professor do CEFET-MG - Belo Horizonte (MG), Brasil.

\section{Cristina Guimarães César}

Doutora em Engenharia Civil pela Universidade Federal de Santa Catarina (UFSC) - Florianópolis (SC), Brasil. Professora do Curso de Engenharia de Produção Civil do CEFET-MG - Belo Horizonte (MG), Brasil.

\begin{abstract}
Resumo
O objetivo deste artigo foi expor a atual conjuntura da geração de resíduos em Belo Horizonte de forma a apresentar as principais características dos resíduos de construção civil (RCC) acerca de sua tipologia, origem, predominância em sua composição, além de dados a respeito das obras que o geraram, como seu padrão construtivo e tipo de edificação. Os resultados demonstraram que a maior parte dos rejeitos gerados na capital é de base cerâmica, oriundos de obras de reformas residenciais de casas, classificadas em padrão normal de acabamento, localizadas, sobretudo, nas regionais Centro-sul e Pampulha. Pela determinação destas características foi possível estabelecer recomendações aplicáveis tanto às usinas de reciclagem como ao sistema de gerenciamento de resíduos da capital como forma de minimizar as causas da variabilidade dos agregados reciclados gerados a partir dos RCC.
\end{abstract}

Palavras-chave: gerenciamento de resíduos; reciclagem; agregados reciclados; variabilidade.

\section{Abstract}

The aim of this article was to expose the current state of affairs regarding the generation of waste in Belo Horizonte so as to present the main characteristics of construction civil waste (CCW) involving their typology, origin, predominance in their composition, as well as data about the construction sites that generated them, their construction pattern and type of building. The results show that the majority of the waste generated in Belo Horizonte is of ceramic base, deriving from house renovations construction sites classified as normal finishing standard located mainly in the center south and Pampulha areas. By determining these characteristics it was possible to establish recommendations applicable to the recycling plants as well as to the waste management system in Belo Horizonte to minimize the causes of the variability of the recycled aggregates generated from construction civil waste.

Keywords: waste management; recycling; recycled aggregates; variability.

\section{Introdução}

Até meados do último século as questões relativas ao desenvolvimento industrial sobrepunham-se àquelas correlatas ao meio ambiente sem que fosse dada a devida importância aos reflexos da interação entre o homem, suas atividades e o meio no qual estão inseridos sendo os assuntos decorrentes da interação entre o homem e seu habitat apenas objeto de estudo de pesquisadores que divulgavam suas observações sem nenhum respaldo por parte das empresas e do governo (FERREIRA; NOSCHANG; FERREIRA, 2009).

Atualmente, quando avaliadas as exigências sociais e legais propostas ao setor da construção civil, as atividades correlatas ao beneficiamento e posterior utilização dos resíduos de construção civil (RCC) têm sido vistas como um dos meios para o fechamento de seu ciclo produtivo. Esta atividade tem-se apresentado viável quando demonstrados os benefícios 
ambientais oriundos da incorporação destes rejeitos em novos produtos ou pelo seu emprego direto como material substituto aos agregados naturais.

A utilização destes materiais reciclados traz ainda como vantagens a redução de custos com deposições irregulares e como consequência minimiza o abandono de rejeitos perto das zonas urbanas. Em seu trabalho, Inyang (2003) expõe que o desenvolvimento de infraestrutura física para operações civis e industriais oferece oportunidades significativas para o emprego de material reciclado em grandes quantidades.

Ainda como justificativa para a reutilização dos RCC, é exposto por John (2003)1 apud Peixoto et al., (2009) que a indústria da construção seja responsável pelo uso de 15 a 50\% do montante de todo o recurso natural consumido pela sociedade. Peixoto et al. (2009) relatam ainda que o consumo de agregados naturais no Brasil varia entre 1 a 8 toneladas/per capita $\mathrm{x}$ ano e que o uso deste insumo para a produção de concreto atinge índices de 220 milhões de toneladas por ano.

Sendo assim, como forma de minimizar o emprego indiscriminado de materiais virgens, a degradação ambiental dada pela grande extração de recursos naturais e a deposição de rejeitos em aterros ou locais não regulamentados, a reciclagem e reutilização dos resíduos de construção civil firma-se como uma alternativa a considerar quando avaliados os requisitos de sustentabilidade.

Contudo, um dos maiores problemas quanto ao emprego dos agregados reciclados reside no fato de sua variabilidade, propriedade intrínseca, que reduz a gama de utilização destes insumos nas atividades inerentes à construção civil. Porém, quando adotadas ações de controle desta propriedade é possível ampliar seu emprego, o que ocasiona um incremento no beneficiamento dos RCC além de proporcionar ganhos ambientais por meio da redução da extração de materiais virgens, redução da poluição e ganhos econômicos quando avaliada a redução de custos atingida pela minimização de gastos com materiais em obras, por exemplo.

Mas para que se promova uma expansão do uso dos agregados reciclados é necessário que se demonstre que a sua utilização não implica em riscos, sejam eles ambientais, de segurança ou de qualquer espécie. Desta forma, o material produzido a partir dos RCC deve apresentar um desempenho equivalente ou superior àqueles que visa substituir.

Ainda como forma de criar mecanismos de controle da variabilidade é preciso que se estabeleçam também um estudo sobre a caracterização dos RCC. Desta forma, a pesquisa desenvolvida junto às usinas de reciclagem de resíduos de Belo Horizonte teve por objetivo a avaliação da tipologia dos RCC entregues para beneficiamento como forma de apresentar suas características acerca de sua origem, predominância em sua composição, além de dados a respeito das obras que o geraram, como seu padrão construtivo e tipo de edificação.

Por meio desta caracterização foi possível apresentar recomendações que são aplicáveis ao sistema de gerenciamento de resíduos e às atividades desenvolvidas nas usinas de reciclagem como forma de introduzir ações corretivas, preventivas e de melhoria no sistema de gestão de RCC implantado na capital o que reflete em ganhos significativos para o sistema de gestão de resíduos da construção civil na cidade de Belo Horizonte (MG).

\section{Métodos}

Na elaboração da metodologia desenvolvida para este estudo, foram avaliadas hipóteses sobre a influência de fatores externos como causa da variabilidade dos agregados reciclados, tais como:

- A origem dos RCC no que diz respeito a serem rejeitos provenientes de novas construções, demolição, reformas, terra bruta (incluindo-se nesta classificação as escavações e limpeza de terreno), rejeitos mistos (compostos por resíduos provenientes de fontes diversas) e resíduos oriundos das unidades de recebimento de pequenos volumes (URPV);

- A interferência da tipologia da construção na qualidade dos agregados obtidos a partir dos RCC reciclados. É necessário que se diga que esta avaliação da tipologia de construção refere-se ao padrão de obra executada ou demolida (baixo, normal e alto padrão). Estas tipologias foram baseadas naquelas apresentadas pela NBR-12721 (ABNT, 2007) — avaliação de custos unitários de construção para incorporação imobiliária e outras disposições para condomínios edilícios;

- A correlação existente entre a questão logística das atividades de gerenciamento de RCC e a variabilidade dos agregados reciclados. É possível inferir que a hipótese de se ter agregados reciclados de melhor qualidade é reforçada quando uma usina encontra-se instalada em um local onde ela receba uma grande quantidade de RCC provenientes de obras de construção e demolição de alto padrão.

Postas estas hipóteses foi elaborado um questionário com itens que abordam dados a respeito da origem dos RCC, o padrão da obra que originou os resíduos, localização da obra geradora e outras questões que permitiram traçar o panorama dos rejeitos entregues nas usinas de Belo Horizonte para beneficiamento.

Estes questionários foram aplicados para cada uma das 3 usinas de reciclagem (Usina Estoril, Usina BR-040 e Usina Pampulha) ao longo de 1 semana durante 4 meses consecutivos nos anos de 2010 e 2011. Para cada dia de trabalho, foram aplicados dez questionários, sendo divididos em duas etapas: cinco no período da manhã e cinco no período da tarde. Esta proposta é mais bem representada na Tabela 1.

O período de coleta foi estabelecido para que também fosse avaliada a influência da sazonalidade das entregas na variabilidade dos RCC; a decisão de fracionar a aplicação dos questionários durante o dia foi tomada para que se pudesse ter uma maior representatividade nos dados colhidos acerca dos resíduos uma vez que, segundo os técnicos responsáveis, não há um horário que se observe um pico no número de entregas. A quantidade de questionários aplicados foi limitada a 50 unidades devido ao grande volume de entregas durante o mês, e em função do número médio de entregas mensais. No fim do período de 4 meses de coleta de dados foi contabilizado um montante de 600 questionários, sendo 200 de cada uma das 3 unidades de beneficiamento. 
Tabela 1 - Representação da aplicação mensal dos questionários em cada uma das usinas.

\begin{tabular}{llcccccc} 
Semana & & Segunda-feira & Terça-feira & Quarta-feira & Quinta-feira & Sexta-feira \\
Período & Manhã & 5 questionários & 5 questionários & 5 questionários & 5 questionários & 5 questionários \\
$\Sigma$ & Tarde & 5 questionários & 5 questionários & 5 questionários & 5 questionários & 5 questionários \\
& & 10 questionários & 10 questionários & 10 questionários & 10 questionários & 10 questionários \\
\hline Total Mensal & & & 50 questionários & &
\end{tabular}

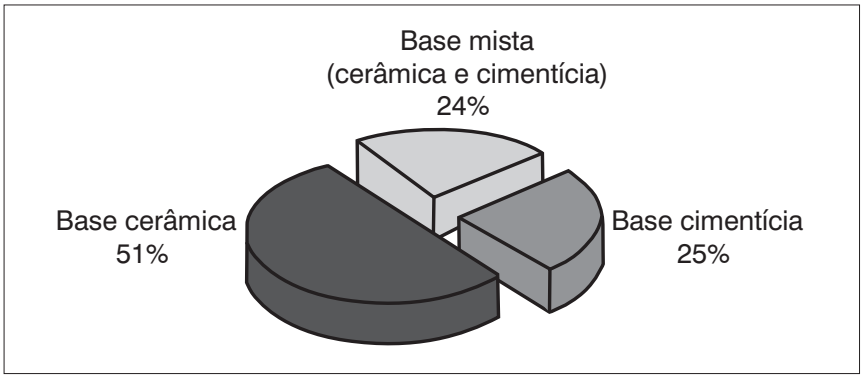

Figura 1 - Contribuição geral: percentual de entregas por predominância do material.

\section{Resultados e discussões}

Guardadas as particularidades apresentadas por cada usina, quando avaliados todos os 593 questionários que puderam ser validados (7 questionários não puderam ser contabilizados por tratarem de dados de entregas que apresentaram material contaminante, não passível de reciclagem) verificou-se que grande parte dos RCC entregues para reciclagem em Belo Horizonte é de base cerâmica, provenientes de obras de reformas residenciais de casas, classificadas em padrão normal de acabamento, localizadas, sobretudo, nas regionais Centro-sul e Pampulha. No que diz respeito à tipologia do resíduo, estes dados confirmaram o que foi exposto no trabalho de Pinto e Gonzáles (2005)², apud Miranda, Angulo e Careli, (2009) que afirmaram que, nos municípios brasileiros, são predominantes aqueles provenientes de obras de reformas. Estes dados são apresentados nas Figuras 1-4.

Definindo-se a variabilidade dos RCC como a característica determinada por diversos fatores, como por exemplo, a inconsistência na composição dos materiais que são encontrados nos resíduos, ampla dispersão entre as atividades de construção e demolição, dentre outros, os resultados demonstram a necessidade do efetivo controle deste item já que os resíduos oriundos de obras de reforma apresentam características diferenciadas em sua formação uma vez que as áreas reparadas são bastante distintas e utilizam materiais de fontes diversificadas.

No que diz respeito à sazonalidade, como aquelas correlatas à alteração do número de entregas devido a fatores climáticos e expansão do mercado imobiliário ou ainda alteração da predominância do material devido a modificações introduzidas por novos materiais, é possível dizer que o perfil apontado reflete o comportamento observável ao longo de um período mais extenso caso não haja alterações significativas no mercado da construção da cidade, sendo assim representativo no que tange às particularidades dos RCC gerados na capital.

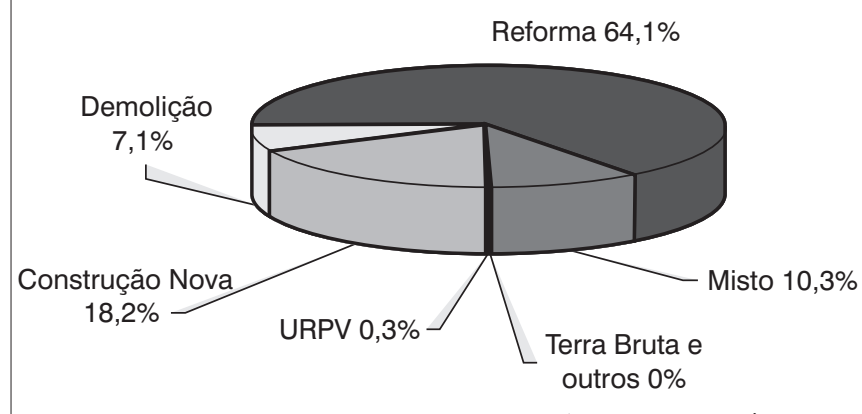

URPV: unidade de recebimento de pequenos volumes; são unidades distribuídas entre as nove regionais de Belo Horizonte responsáveis pelo recebimento de RCC entregues por pequenos geradores, em uma quantidade máxima de até $2 \mathrm{~m}^{3}$ por dia.

Figura 2 - Contribuição geral: tipo de resíduo (percentual de contribuição).

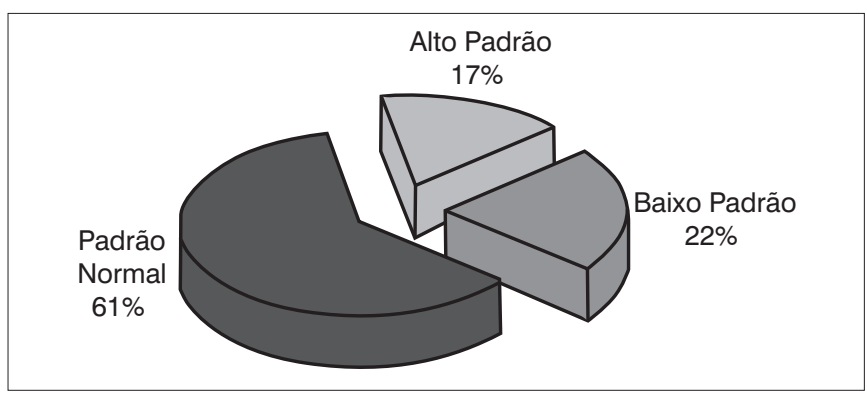

Figura 3 - Contribuição geral: percentual de entregas por padrão de obra.

Os resultados demonstraram que do total de $3.727 \mathrm{~m}^{3}$ de resíduos avaliados no período, o índice de entregas de RCC originados em obras residenciais ( $84,3 \%$ das entregas) são maiores do que aqueles apontados para obras comerciais e mistas (comercial/residencial). Foi verificado também que o número de obras referente a casas é superior àquele apresentado para obras que geralmente são executadas por grandes geradores, como prédios de apartamentos não populares e casas/apartamentos populares, denominados também por conjuntos habitacionais. Estas informações são apresentadas nas Figuras 5 e 6.

Desta forma, poder-se-ia inferir que as usinas atenderiam de maneira prioritária e direta aos pequenos geradores, fato que explicaria o baixo índice de entregas de RCC originários das URPV. Contudo, cabe observar que os grandes geradores também podem ser os responsáveis por obras de reforma de qualquer natureza independente de seu porte. ${ }^{3}$ 


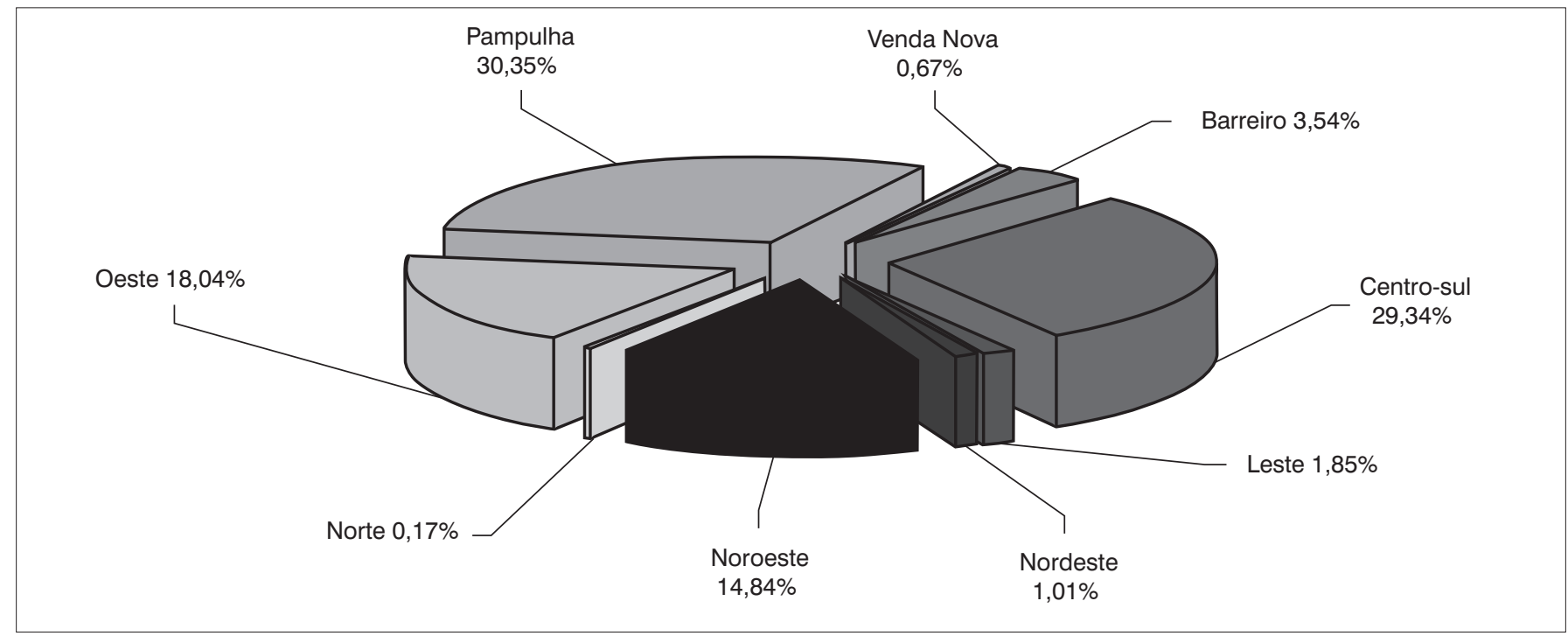

Figura 4 - Contribuição geral: percentual de entregas por regional.

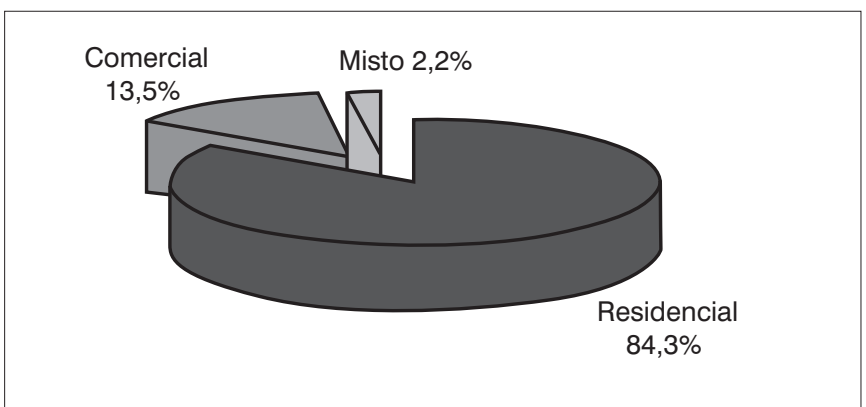

Figura 5 - Contribuição geral: entregas por categoria de obras.

Portanto, não é possível afirmar que o baixo índice de entregas de RCC oriundas das URPV esteja relacionado ao perfil do construtor ou porte da obra, por exemplo. Logo, o fato de haver um alto índice de entregas de resíduos provenientes de obras de reformas residenciais reflete uma tendência das obras executadas na cidade no período da pesquisa.

Sendo assim, sabendo-se que as usinas recebem volumes acima de $2 \mathrm{~m}^{3}$, conclui-se que seja necessário um controle mais efetivo junto aos pequenos geradores, uma vez que quando observado o total de obras de pequeno porte, observa-se a produção de grandes volumes de resíduos que podem ser dispensados em locais clandestinos caso não haja uma fiscalização efetiva.

Quando confrontados os resultados obtidos com as hipóteses investigadas verificou-se que em todas as usinas as entregas são, em sua maioria, de resíduos gerados em obras de padrão normal, sendo que a usina BR-040 foi a que apresentou o maior número de entregas de obras de alto padrão, enquanto as usinas Estoril e Pampulha, que utilizam os agregados reciclados como insumo na produção de blocos de concreto, apresentaram entregas de obras de baixo padrão mais expressivas que a primeira (Figura 7). Porém, este fato por si só não é determinante para que

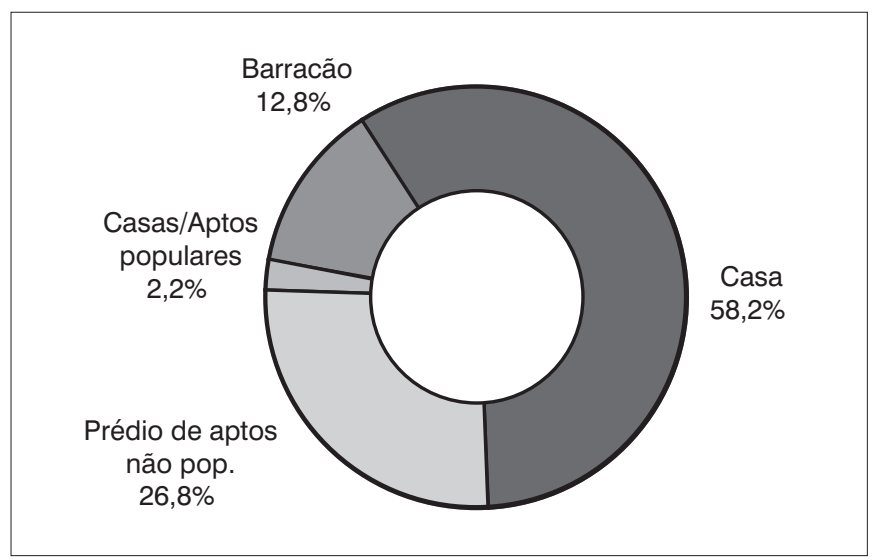

Figura 6 - Contribuição do tipo de construção no total de categoria de obras residenciais.

defina qual das usinas produz agregados reciclados de melhor qualidade no que diz respeito as suas características físicas e de empregabilidade, o que remete à necessidade de um controle físico dos insumos produzidos a partir destes resíduos. Há de se dizer ainda que o fato das entregas terem sido originárias em grande número de obras localizadas nas regionais Centro-sul e Pampulha, locais onde há uma grande concentração de obras padrão elevado, não foi determinante para que as usinas recebessem RCC de obras de alto padrão.

A expressividade de entregas de resíduos de base cerâmica é explicada pelo fato destes RCC terem sido originados em obras de reforma de casas, que em geral, são intervenções menos vultosas, que reparam áreas distintas e que utilizam materiais mais comumente empregados na construção civil como tijolos, telhas e revestimentos cerâmicos em detrimento àqueles empregados em obras de grande porte como, por exemplo, o concreto. 


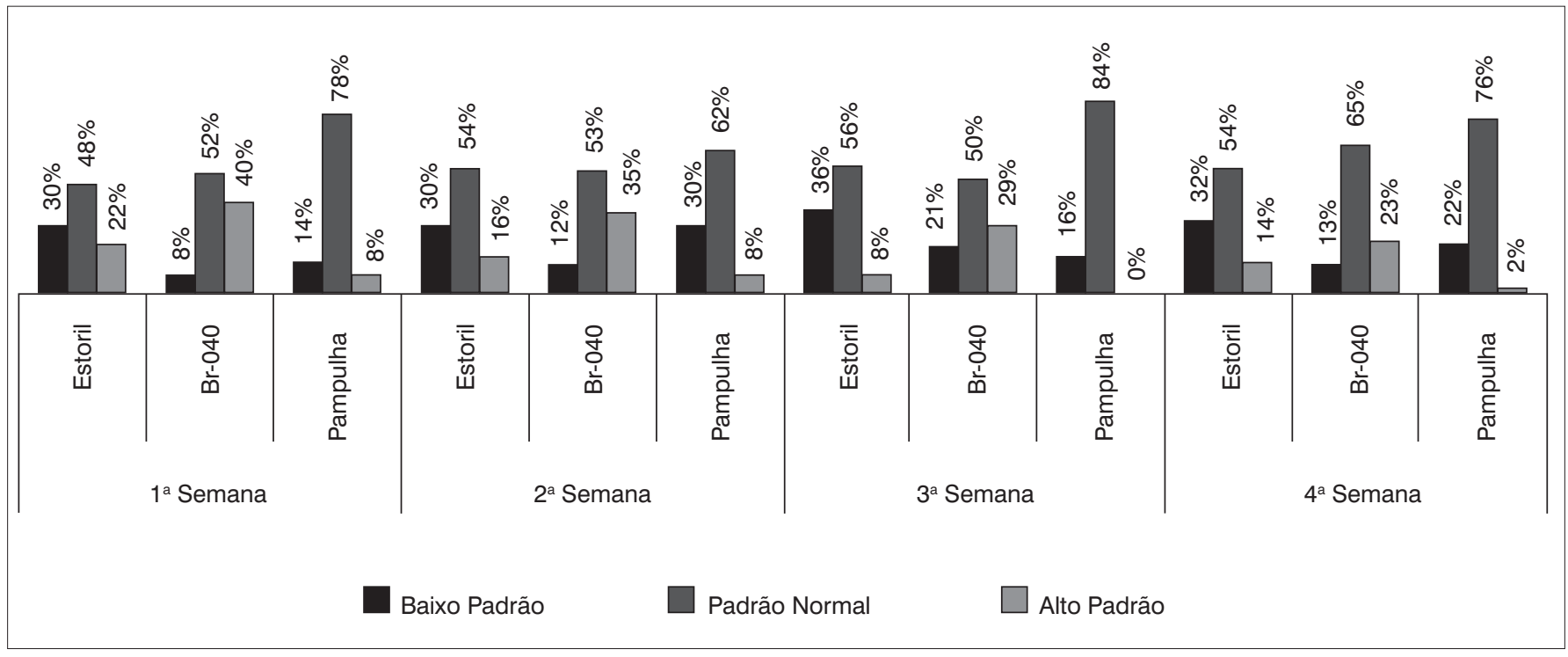

Figura 7 - Contribuição geral (por semana): percentual de entregas por padrão de obra.

Estes resultados expõem a necessidade do estabelecimento de melhorias que sejam diretamente aplicáveis ao sistema de gerenciamento de resíduos da capital bem como às atividades desenvolvidas nas usinas como forma de elevar o padrão de qualidade dos agregados reciclados produzidos, sobretudo no que diz respeito ao controle e redução de sua variabilidade.

Como resultado deste estudo foram propostas recomendações que surgiram da necessidade da correta identificação dos geradores, da quantificação dos RCC que são encaminhados para beneficiamento bem como sua origem, conforme preconizado na Resolução CONAMA no 307 (BRASIL, 2002).

Além disso, o seu aspecto técnico advém da necessidade da análise e controle dos resíduos como forma de caracterizá-los ampliando assim o seu emprego por meio da redução de sua variabilidade, etapa esta, hoje não desenvolvida.

Uma destas recomendações fundamenta-se na criação de um sistema de coleta de dados de caracterização inicial dos RCC entregues para reciclagem que, em suma, propõe uma parceria entre a Superintendência de Limpeza Urbana (SLU), a Secretaria Municipal Adjunta de Regulação Urbana e a Secretaria Municipal de Meio Ambiente, responsáveis pela aprovação de projetos/regularização de edificações e licenciamento ambiental de empreendimento de impactos, respectivamente.

Estes dois últimos órgãos passariam a ser responsáveis também pela aprovação de projetos de gerenciamento de resíduos que devem ser apresentados quando da aprovação/licenciamento de novas edificações, conforme preconizado pela Resolução CONAMA no 307.

Há que se esclarecer que atualmente os dados sobre as edificações licenciadas não são disponibilizadas à SLU. Desta forma, as informações inerentes aos RCC gerados por estas obras seriam levantados e repassados à SLU, responsável pela compilação e divulgação de dados. Estas informações seriam adicionadas àquelas já levantadas pela própria Superintendência e passariam a fazer parte de um banco de dados histórico que nortearia as ações voltadas à administração do sistema de gerenciamento de resíduos da capital no que diz respeito à necessidade de reformulação de estratégia de recebimento de resíduos, ampliação da rede de URPV, elaboração de novas leis municipais aplicáveis à cadeia da construção civil, dentre outros.

Como benefício, esta medida reforçaria as ações hoje adotadas e adequariam o Programa Municipal de Gestão de Resíduos às determinações legais postas pela Resolução CONAMA no 307. Além disto, possibilitaria a obtenção de dados mais confiáveis e estruturados, uma vez que são poucas as informações que são divulgadas a respeito dos RCC.

Como medidas técnicas a pesquisa propõe que seja estabelecido um controle, em termos físicos, das propriedades dos agregados reciclados. Isto aumentaria a possibilidade do uso direto deste material ou sua incorporação em produtos como as peças pré-moldadas de concreto sem função estrutural.

A proposição destes aspectos práticos tem por objetivo estabelecer critérios mínimos de procedimento aplicáveis à caracterização física dos agregados reciclados por meio dos ensaios laboratoriais específicos.

Como contribuição, esta recomendação possibilitaria, dentre outras observações, identificar quais as propriedades físicas a serem tratadas para ampliação do uso destes agregados, facilitaria o estudo de novos materiais que venham a utilizar estes reciclados como insumo, aumentaria seu valor agregado, possibilitaria uma maior aceitação deste material junto ao mercado por se tratar de um insumo devidamente controlado. Além disso, possibilitaria o estabelecimento de parâmetros de comparação entre os materiais produzidos pelas três usinas, que por sua vez forneceria subsídios para que se obtenham informações necessárias à tomada de decisão sobre medidas de gerenciamento que possam ser reformuladas ou aplicadas.

Ainda como medida técnica a ser aplicada para a redução da variabilidade da matéria-prima (RCC) e consequentemente do insumo beneficiado (agregados reciclados), propõe-se a separação dos materiais em pilhas distintas seguida de sua homogeneização. A separação dos RCC recebidos em pilhas distintas de acordo com sua predominância, ou seja, materiais de base 
cerâmica, cimentícia e mista, traria como benefício a consequente segregação dos agregados reciclados o que facilitaria a utilização mais viável de cada um dos matérias gerados de acordo com o emprego ao qual se destina.

Esta medida favorece ainda a análise dos parâmetros físicos, o que beneficiaria os estudos e desenvolvimento de materiais compostos que utilizem esses insumos além da obtenção de um agregado de maior aplicabilidade obtido pela mistura dos materiais oriundos destas três bases.

Outro benefício gerado pela separação dos RCC/agregados em pilhas distintas seria a otimização do processo de fabricação de blocos de concreto sem função estrutural nas usinas Estoril e Pampulha, o que facilitaria também o desenvolvimento de novos artefatos de concreto que utilizam de agregados gerados a partir de RCC de base cimentícia.

Em associação à proposta da adoção de pilhas de separação recomenda-se que seja adotada a homogeneização do material antes e após o beneficiamento, medida que não é executada atualmente, sendo todo material recebido e processado estocado pela simples deposição de acordo com os fluxos das atividades.

Angulo et al. (2001) verificaram em um de seus estudos que a utilização de pilhas de homogeneização trouxe benefícios para o controle da variabilidade de todas as propriedades físicas analisadas (massa unitária, massa específica, absorção de água e módulo de finura), sendo que todas elas tendem a se aproximarem de um valor médio, exceto a massa unitária.

Sendo assim, o controle da variabilidade por meio da adoção destas etapas são medidas consistentes e justificáveis tanto para a valorização dos agregados reciclados como para a homogeneidade com vistas à produção de componentes que se utilizem deles.

\section{Conclusões}

Os dados apresentados na pesquisa demonstram que, embora Belo Horizonte seja uma referência na gestão de resíduos de construção civil, é necessário que algumas medidas de controle e análise dos resíduos e dos agregados reciclados sejam estabelecidas. Desta forma elevar-se-ia o padrão das atividades desenvolvidas nas usinas e consequentemente a qualidade dos insumos produzidos o que reforça as medidas de fechamento do ciclo da construção civil como forma de minimização dos impactos ambientais.

Além disso, essas recomendações contribuirão para a adequação do sistema de gestão de resíduos da capital ao que está determina do pela Resolução CONAMA n 307 , no que diz respeito à correta identificação dos geradores e as atividades que por eles devem ser desenvolvidas para a correta deposição de resíduos.

A parceria entre os órgãos municipais mostra-se benéfica uma vez que abre oportunidades para discussões efetivas a respeito das atividades que hoje são adotadas e que podem ser melhoradas por meio de trabalhos que se complementem. Isso trará ganhos à municipalidade por meio de um controle mais efetivo da rede de gerenciamento, uma vez que os dados compartilhados entre a SLU, Secretaria Municipal de Meio Ambiente e Secretaria Municipal Adjunta de Regulação Urbana fornecerão subsídios para que seja criado um banco de dados confiável acerca da geração dos RCC em Belo Horizonte, com informações consistentes que servirão como instrumento para a tomada de decisões quanto ao planejamento e aprimoramento do programa de deposição de resíduos na capital.

A proposta de controle de estocagem e homogeneização como maneira de promover a melhoria das propriedades físicas dos agregados reciclados, somadas à sua devida caracterização traz como benefício a possibilidade de se agregar valor a estes insumos, o que consequentemente poderia promover um aumento no emprego destes materiais, respeitadas as restrições normativas e de segurança.

Além de representarem uma forma efetiva e viável para o controle da variabilidade destes insumos, essas medidas promovem uma melhor aceitação deste material no mercado por tratar-se de produtos devidamente controlados, além de possibilitar ganhos financeiros promovidos pela redução de custos em obras que utilizem os agregados reciclados.

\section{Referências}

ANGULO, S.C.; MIRANDA, L.F.R.; SELMO, S.M.S; JOHN, V.M. (2001) Utilização de pilhas de homogeneização para controle de agregados miúdos de resíduos de construção e demolição reciclados. In: Construção 2001: por uma construção sustentável, 2001, Lisboa. Anais... Lisboa: Instituto Superior Técnico. p. 713-720.

ASSOCIAÇÃO BRASILEIRA DE NORMAS TÉCNICAS (ABNT). (2007) Avaliação de custos unitários de construção para incorporação imobiliária e outras disposições para condomínios edilícios - Procedimento NBR-12721. Rio de Janeiro: ABNT.

BRASIL. Ministério do Meio Ambiente. Conselho Nacional do Meio Ambiente (CONAMA). (2002) Resolução no 307, de 05 de Julho de 2002. Dispõe sobre a gestão de resíduos da construção civil. Brasília: Ministério do Meio Ambiente.

FERREIRA, D.D.M.; NOSCHANG, C.R.T.; FERREIRA, L.F. (2009) Gestão de resíduos da construção civil e de demolição: contribuições para a sustentabilidade ambiental. In: V Congresso Nacional de Excelência em Gestão, 2009, Niterói. Anais... Niterói: Universidade Federal Fluminense. p. 1-23.

INYANG, H.I. (2003) Framework for recycling of waste in construction. Journal of Environmental Engineering, v. 129, n. 10, p. 887-898.

MIRANDA, L.F.R.; ANGULO, S.C.; CARELI, É.D. (2009) A reciclagem de resíduos de construção e demolição no Brasil: 1986-2008. Revista Ambiente Construído, v. 9, n. 1, p. 57-71.

PEIXOTO, R.A.F.; PAULA, D.P.; SILVA, K.A; RIBEIRO, T.H.R.; SILVA, M.J. (2009) Analysis for application of steel slag in the production of concrete block paving. In: 9th International Conference on Concrete Block Paving, 2009, Buenos Aires, Argentina. 9th International Conference on Concrete Block Paving. v. 1. 